\title{
A Dinâmica de Autoridade na Villa: 0 Vilicus e a Administração da Propriedade Agrícola
}

\author{
The Dynamics of the Authority in the Villa: the Vilicus and the \\ Administration of the Agricultural Proprierty
}

\section{Fabiana Martins Nascimento ${ }^{1}$}

\begin{abstract}
1 Doutoranda e mestre pelo Programa de Pós-Graduação em História Comparada (PPGHC-UFRJ), membro do Laboratório de História Antiga (LHIA-UFRJ) e orientada pelo Prof. Dr. Deivid Valério Gaia (LHIA-UFRJ). O presente artigo compõe a pesquisa desenvolvida no projeto intitulado, "Estratégias e táticas econômicas para a administração da propriedade agrícola: uma análise comparada dos tratados agrícolas de Catão, Varrão e Columella". E-mail para contato: fabianamnm@gmail.com.
\end{abstract}

Recebido em 05 de maio de 2020; Aceito em 10 de junho de 2020

\section{Resumo}

O presente artigo tem por objetivo analisar de que forma se estruturava a dinâmica de autoridade entre os sujeitos envolvidos no processo produtivo da villa. A presente análise se concentrará nas relações que o vilicus, o escravo administrador, mantinha tanto com seu superior, o proprietário (e também seu senhor) quanto com seus subordinados, a vilica, os demais escravos.

Palavras-chave: Catão; Varrão; Columella; Economia Romana; Villa.

\section{Abstract}

This article aims to analyze how the dynamics of authority between the subjects involved in the productive process in the villa was structured. The present analysis will focus, therefore, in the relationships that the vilicus, the slave manager, maintained both with his superior, the owner (and also his master) and with his subordinates, the vilica and the other slaves.

Keywords: Cato; Varro; Columella; Roman economy; Villa.

\section{Introdução}

A villa constituiu um sistema econômico de grande relevância no período que compreendeu os século II a.C. e II d.C. Esse tipo de propriedade fundiária produzia os principais tipos de culturas mais consumidas tanto na cidade de Roma quanto no Império de modo geral. Sua produção se direcionava, portanto, aos mercados. Grande 
ISSN 1982-8713

parte da informação que temos a respeito do funcionamento desse sistema se encontra em três tratados agrícolas produzidos entre os séculos II a.C. e I d.C. Ainda que se trate de documentos normativos, os tratados De Agri cultura de Catão, De Re Rustica de Varrão e De Re Rustica de Columella nos informam a respeito das formas como a elite romana, principal engajada nesse tipo de empreendimento, concebia a administração da villa - ainda que se trate de idealizações, não é absurdo considerar que os autores se basearam nas realidades de seus períodos, tanto para propor novas práticas quanto para perpetuar práticas antigas.

A estratégia para a administração desse tipo de propriedade proposta pelos agronômos em seus tratados é classificada por Jean Andreau como intermediária entre a delegação ativa e a delegação passiva. Por delegação ativa o autor compreende aquela voltada exclusicamente para o lucro e pouco compatível com a posição social dos membros da elite romana, que não os permitia se dedicarem integralmente as operações de nenhuma atividade econômica. Já a delegação passiva seria aquela na qual todas as decisões administrativas ficariam a cargo de terceiros sem a participação do proprietário, mesmo que esporádica. A estratégia dos agrônomos se situa dentre essas duas uma vez que equilibra a busca por lucro com o estilo de vida dos proprietários (ANDREAU, 2004, p. 84). Acreditamos que essa ideia é bastante coerente para que se compreenda a natureza das orientações de Catão, Varrão e Columella. Isso porque, conforme discutiremos, as orientações dos autores demonstram grande preocupação com a eficiência produtiva dos escravos, mas sem que o envolvimento cotidiano do proprietário nas operações fosse a solução.

Uma das principais características da villa enquanto sistema produtor consiste, portanto, no absenteísmo dos proprietários. Considerando o grande volume de obrigações sociais e, sobretudo, políticas dos membros da elite romana na cidade de Roma, não sobrava tempo para que estes homens pudessem administrar presencialmente suas propriedades agrícolas. Sendo assim, a administração cotidiana ficava a cargo de um agente específico, o vilicus. Logo, esse agente constituía a figura de 
autoridade máxima da villa na ausência do proprietário. Os modelos administrativos propostos por Catão, Varrão e Columella orientam a respeito de três grandes pontos relativos ao vilicus: as características físicas e morais necessárias a ele, seu escopo de ação e o tipo de relação que deveria estabelecer com os escravos que compunham a mão de obra fixa da propriedade. Por essa razão dividimos o presente artigo em três seções, cada uma destinada a discutir cada um desses pontos. Antes, porém, discorreremos brevemente a respeito da estrutura administrativa da villa.

Os proprietários poderiam escolher entre dois modelos gerais de administração da villa, o que Jean-Jacques Aubert chamou de vilicus system, no qual um vilicus administrava a propriedade e a mão de obra envolvida no processo produtivo. Ou o arrendamento, isto é, o aluguel de lotes de terras a rendeiros que deveriam pagar pelo seu uso ao proprietário (AUBERT, 1994, p, 161). Columella é o único autor que deixa explícita as condições desses dois modelos. Catão e Varrão parecem indicar apenas as condições do vilicus system - essa questão gera discussões, mas não é nosso objetivo nos atermos a ela no presente texto. A vantagem de implementar a exploração direta da terra, de acordo com Aubert, estava na possibilidade do agente, o vilicus, conduzir os negócios do proprietário sem a necessidade de sua supervisão contínua. No caso do arrendamento o proprietário (ou procurator) deveria se ocupar de cobrar o pagamento do aluguel e supervisionar as condições em que os arrendatários mantinham a propriedade. O objetivo do vilicus system só seria cumprido, portanto, se não fosse necessário que o proprietário constantemente supervisionasse a administração da propriedade (AUBERT, 1994, p. 161).

Apesar da necessidade de confiança que esse sistema administrativo demandava, visto que a supervisão seria espaça, o que podemos observar das orientações dos agrônomos é que a relação entre proprietário e vilicus estava envolta em desconfianças. Essa quadro, a nosso ver, se relaciona ao status servil do agente ainda que Aubert aponte que o vilicus poderia ser em alguns casos um homem livre ou liberto, sobretudo no período imperial (AUBERT, 1994, p, 149). O escravo desonesto e 
ISSN 1982-8713

mentiroso, é seguro afirmar, constitui um tópos da literatura latina. Como aponta Sandra Joshel, um ditado romano afirma que um homem tem como inimigos a mesma quantidade de escravos que possui (JOSHEL, 2010, p. 220). Em decorrência desse panorama, Aubert aponta que os agrônomos estavam mais preocupados em amenizar a potencial destruição que poderia ser causada pelo vilicus do que maximizar os lucros da propriedade (AUBERT, 1994, p. 132).

Essa leitura, a nosso ver, minimiza os objetivos econômicos dos proprietários, ponto que é central para compreendermos os modelos administrativos propostos por Catão, Varrão e Columella, como apontado. Ainda que os agrônomos desconfiassem do vilicus, consideravam que o vilicus system conciliava seus objetivos econômicos com seu modo de vida - que tornava o absenteísmo necessário. Para contornar tal desconfiança os agrônomos formularam modelos de gestão que buscavam controlar esse agente e, ao mesmo tempo, o tornasse capaz de manter a ordem e aumentar a produtividade da villa.

\section{Requisitos físicos, morais e intelectuais do Vilicus}

Para que pudesse cumprir seu papel o vilicus deveria ter características específicas e se encaixar em um ideal moral e comportamental. No De Agri Cultura Catão não nos informa de forma extensa sobre os requisitos do escravo para que esse ocupasse a função de vilicus, mas a listagem das obrigações do agente apresentada no capítulo 5 nos permite traçar certas características requeridas na perspectiva do autor. O vilicus deveria ter bons princípios, essa seria uma de suas obrigações. Além disso, o agente deveria ser um escravo contido. Não propício a vícios e que vivesse uma vida simples e focada na execução de suas obrigações na propriedade (CATÃO, De Agri Cultura, 5). Sabemos a partir de Plutarco que Catão buscava simplicidade e austeridade na sua conduta pessoal e que a ostentação ia contra esse estilo de vida. Plutarco afirma ainda que Catão não tinha por hábito gastar muito com escravos, pelo contrário, os 
comprava a preço baixo, os treinava e vendia a preços altos (PLUTARCO, Vidas Paralelas, Catão o velho, 43.1). Sendo assim, o autor possivelmente não trabalha com a ideia de comprar um escravo treinado como vilicus, mas sim de comprar um escravo e treiná-lo e moldá-lo da forma como bem entendesse. No entanto, Catão não informa seus leitores a partir dessa possibilidade. Não temos como precisar o porque da escassez de informação em relação as características do vilicus, mas é possível que Catão considerasse mais importante delinear as obrigações do agente do que seus atributos.

Dos três autores estudados, Varrão é o único que restringe o uso da palavra vilicus a uma única citação, no capítulo 2 do primeiro livro do seu De Re Rustica, no qual afirma que a palavra vilicus deriva da palavra villa e, sendo assim, a existência do vilicus estaria condicionada a esse tipo de propriedade (VARRÃO, De Re Rustica, 1.2.14). No restante de seu tratado, sobretudo no capítulo 17 do primeiro livro, no qual o autor se dedica a tratar da mão de obra escrava, Varrão mobiliza a palavra praefectos, traduzida por Harrison Boyd Ash e Willian Davies Hooper como foremen (ASH; HOOPER, 1935, p. 227) e por Matheus Trevizam como chefe (TREVIZAM, 2012, p. 59). Essa ausência da palavra vilicus no restante do De Re Rustica de Varrão não significa, a nosso ver, que esse tipo de agente não fazia parte do modelo administrativo varroniano, mesmo porque o autor o cita no capítulo 2, conforme apontado. Uma possível explicação consiste na ideia de que Varrão escrevera seu tratado para o proprietário e para o vilicus e por essa razão não cita recomendações sobre o agente de forma direta - ideia que está de acordo com a orientação de que os escravos que liderassem soubessem ler e escrever. Consideramos, portanto, que as orientações do autor no capítulo 17 do primeiro livro a respeito do praefectos podem ser aplicadas ao vilicus, visto que esse seria o chefe dos chefes.

Varrão orienta que o escravo a ser designado para o cargo de vilicus fosse instruído e soubesse ler e escrever (VARRÃO, De Re Rustica, 1.17. 4). O que o autor parece indicar com essa recomendação é a possibilidade do proprietário deixar por escrito as recomendações ao agente, bem como para que esse prestasse contas e 
NEARCD: Revista Eletrônica de Antiguidade 2020, Volume XII, Número I - ISSN 1982-8713

Núcleo de Estudas da Antiguidade -NEA

Universidade do Estada do Rio de Janeiro

ISSN 1982-8713

mantivesse registros a respeito da administração da propriedade. Ainda que o autor não oriente a respeito de tais questões, acreditamos que a orientação para a instrução do vilicus só seria útil com esses fins. A princípio, analisando essa característica, acreditamos ser plausível sugerir que o vilicus deveria possuir uma formação anterior ao exercício de sua função e, consequentemente, provir "de fora do campo", visto que era pouco provável que os escravos empregados no meio rural possuíssem instrução prévia. No entanto, Jesper Carlsen afirma que o vilicus poderia ou não ter formação ou treinamento prévio. Mobilizando como referência a defesa de Cícero em favor de Plancio, na qual o autor compara as obrigações do vilicus com as obrigações de um magistrado, Carlsen afirma que a comparação de Cícero pode indicar que não existia um treinamento profissional formal para esse tipo de agente no fim do período Republicano e, consequentemente, escravos agrícolas experientes e competentes eram difíceis de serem obtidos no mercado (CARLSEN, 2013, p. 93-95). Columella um século depois discutiria a questão do treinamento do vilicus no seu De Re Rustica, no qual se queixa que não existia quem treinasse escravos para ocuparem tal função, apesar de sua extrema importância ${ }^{39}$.

Logo, o vilicus poderia ser comprado "pronto" - ou seja, treinado-, mas seu valor seria alto, comparável ao de um escravo de luxo. Não é claro, portanto, de onde provinham esses agentes - se eram comprados treinados nessa função ou se seria o proprietário que o instruiria. Carlsen afirma que é possível sugerir que o treinamento

\footnotetext{
${ }^{39}$ Columella se queixa a respeito da escassez de locais de formação de uilicus e outros profissionais ligados à agricultura. É interessante observar no trecho em que o autor afirma que "enquanto instrutores podem ser encontrados em outras artes que são menos necessárias a vida, para a agricultura não existem nem instrutores e nem pupilos"; o autor procura uma explicação para tal escassez e afirma que a grande dimensão do assunto pode ocasionar certo "temor" a aqueles que desejam aprender ou ensinar esta arte, que "praticamente não tem limites". Columella afirma que a arte da oratória, por exemplo, não deixou de ser ensinada e aprendida porque não existe um orador perfeito, ou filosofo; mas ao contrário, muitas pessoas se encorajaram em adquirir conhecimento (ou parte dele), uma vez que não podem adquiri-lo por completo. Desta forma, não existe motivo para silenciar uma arte apenas por não se conseguir ser perfeito nela. $\mathrm{O}$ autor entende que a complexidade e grandiosidade dos assuntos relacionados à agricultura e seus procedimentos, acaba por assustar os homens, que acabam por se abster de adquirir esse tipo de conhecimento. COLUMELLA, De Re Rustica, Prefácio .4-11.
} 
NEARCD: Revista Eletrônica de Antiguidade 2020, Volume XII, Número I - ISSN 19882-8713

Núcleo de Estudas da Antiguidade -NEA

Universidade do Estada do Rio de Janeiro

ISSN 1982-8713

dos vilicus era informal e possivelmente mais comumente baseado em algum tipo de "auto treinamento", sobretudo no que concernia o gerenciamento dos trabalhadores e as práticas agrícolas, de acordo com o histórico do vilicus (CARLSEN, 2013, p. 93-95). Quanto à alfabetização do agente é possível que o senhor fosse o responsável visto que dificilmente a prática ou a auto-instrução seria o suficiente. A possibilidade de deixar instruções escritas ao vilicus, bem como que esse registrasse as contas e demais ações tornaria mais precisa a avaliação do proprietário a respeito da administração conduzida, um importante instrumento prescrito por Varrão. Essa característica, no entanto, assume um caráter extremamente negativo com Columella, conforme analisaremos a seguir.

Por ter escrito um livro exclusivamente para orientar a respeito do vilicus, Columella é o autor que mais nos informa a respeito desse agente. $O$ autor afirma que o escravo escolhido para essa função não deveria estar nem no seu primeiro estágio da vida e nem no último. Isto é, não deveria se tratar nem de um escravo novo e inexperiente e nem de um escravo já velho e impossibilitado - entre 35 e 65 anos (idade relativamente avançada considerando a média de expectativa de vida na sociedade romana, sobretudo se tratando de um escravo $)^{40}$. Os requisitos exigidos por Columella são mais complexos que aqueles apontados por Catão e Varrão em termos de formação desse agente - o que pode indicar sua insegurança no modelo do vilicus system, bem como pode indicar uma espécie de aperfeiçoamento em relação aos modelos administrativos anteriores. De acordo com o autor:

Então, meu conceito no início é não nomear um vilicus oriundo daquele tipo de escravos fisicamente atraentes, e certamente não daquela classe que se dedicou às ocupações voluptuosas da cidade. Essa classe de servos preguiçosos e sonolentos, acostumados a serem

\footnotetext{
40 A partir de documentos epigráficos Carlsen elabora uma tabela da idades dos vilicus, a maioria das incrições analisadas indicam que os vilicus tinham entre 30 e 49 em propriedades imperiais e entre 50 ou mais em propriedades privadas. A estimativa de Columella, portanto, parece baseada na realidade. CARLSEN, J. Vilici and Roman Estate Managers until AD 284. Roma: L'Erma di Bretschneider, 1995, p. 70.
} 
NEARCD: Revista Eletrônica de Antiguidade 2020, Volume XII, Número I - ISSN 19882-8713

Núcleo de Estudas da Antiguidade -NEA

Universidade do Estado do Rio de Janeiro

ISSN 1982-8713

ociosos, ao Campus, ao Circo a aos teatros, aos jogos, às lojas de comida, às casas obscenas, nunca deixam de sonhar com tais loucuras; e quando eles os carregam para seus campos, o mestre sofra não tanto com a perda do próprio escravo quanto com toda sua propriedade ${ }^{41}$ (COLUMELLA, De Re Rustica, 1.8.1-2).

A indicação de que o uilicus não fosse um escravo da cidade não é explícita em Catão e Varrão apesar dos autores também salientarem a necessidade do indivíduo possuir experiência na agricultura. É possível que a prática de enviar às propriedades agrícolas escravos da cidade para exercerem a função de vilicus fosse comum na época de Columella. O escravo da cidade não teria as características necessárias ao trabalho no campo e carregaria vícios provenientes da vida na cidade, como o apreço pela bebida e pela preguiça. $\mathrm{O}$ autor aponta que aquele que bebe demais se torna descuidado, bem como aquele que dorme demais nunca está a par do que acontece ao seu redor. Columella estabelece, portanto, um conjunto de prescrições morais ainda mais rígido que aquele proposto por Catão e Varrão. A conduta do vilicus deveria ser moralmente correta e eficiente, o autor afirma que o agente deveria ser o primeiro a acordar e marchar para o trabalho sem preguiça, servindo de exemplo para os demais escravos (COLUMELLA, De Re Rustica, 11.1. 13-14.).

Columella continua e afirma que:

Mesmo uma pessoa analfabeta, contanto que possua uma mente retentiva, pode administrar bem os negócios. Cornelius Celsus diz que um vilicus desse tipo traz dinheiro para seu mestre mais frequentemente que o esperado, porque, não conhecendo suas cartas, ele é menos capaz de falsificar relatos ou tem receio de fazê-lo

\footnotetext{
${ }^{41}$ So my advice at the start is not to appoint an overseer from that sort of slaves who are physically attractive, and certainly not from that class which has busied itself with the voluptuous occupations of the city. This lazy and sleepyheaded class of servants, accustomed to idling, to the Campus, the Circus, and the theatres, to gambling, to cookshops, to bawdy-houses, never ceases to dream of these folies; and when they carry them over into their farming, the master suffers not so much loss in the slave himself as in his whole estate.
} 
por meio de um intermediário, pois isso faria outro ciente do engano ${ }^{42}$ (COLUMELLA, De Re Rustica, 1.8.4).

É interessante observarmos que apesar de Columella recomendar um vilicus bem treinado, sobretudo tecnicamente, o autor não orienta que o agente fosse letrado - ao contrário de Varrão. Segundo Columella, uma pessoa sem instrução poderia administrar bem se possuísse uma "mente retentiva". O autor afirma, recorrendo a figura de Cornelius Celsus, que um vilicus desse tipo traria mais dinheiro a propriedade, isso porque sem saber ler e escrever não poderia falsificar as contas (COLUMELLA, De Re Rustica, 1.8.4.).

Enquanto a instrução do vilicus parece constituir uma necessidade ao funcionamento da propriedade no De Re Rustica de Varrão, para Columella poderia constituir um problema. $O$ agente que soubesse ler e escrever seria capaz, alerta o autor, de enganar o proprietário. Esse alerta de Columella pode significar um desgaste do vilicus system devido a possíveis situações de fraudes por parte desse tipo de agente essa ideia estaria de acordo com a orientação do autor de que o proprietário deveria visitar a sede da propriedade com frequência diária, se possível (COLUMELLA, De Re Rustica, 1.1.19-20).

Os requisitos e atributos exigidos do vilicus variam, portanto, de um autor para o outro. No entanto, o que todos indicam é a necessidade de que esse escravo estivesse familiarizado com as atividades desenvolvidas na propriedade, bem como que se encaixasse em certo modelo moral. A ideia de forjar ideais comportamentais aos escravos constituía uma forma de buscar controlá-los no processo de gerenciamento desse tipo de mão de obra. Conforme aponta Keith Bradley, a relação que se estabelecia entre senhor e escravo não se tratava de um contrato que estabelecia direitos e

\footnotetext{
${ }^{42}$ Even an illiterate person, if only he have a retentive mind, can manage affairs well enough. Cornelius Celsus says that an overseer of this sort brings money to his master oftener than he does his book, because, not knowing his letters, he is either less able to falsify accounts or is afraid to do so through a second party because that would make another aware of the deception.
} 
obrigações mútuas entre as partes, mas sim um arranjo que beneficiava apenas um lado (BRADLEY, 1996, p. 6). A existência do escravo se resumia, ou deveria se resumir, ao objetivo que seu senhor buscava com seu corpo e trabalho. Logo, o escravo que ocupasse o posto de vilicus deveria ser moldado a se comportar de uma maneira específica e exemplar. Ainda que ocupasse um cargo de chefia e pudesse ter melhores oportunidades que os demais, o vilicus, assim como todos os escravos, era compreendido como um instrumento a disposição de seu senhor.

\section{A dinâmica de autoridade entre proprietário e Vilicus}

Conforme pontuamos anteriormente, apesar do vilicus ser uma figura essencial no modelo produtivo proposto nos tratados, os autores enxergavam tal escravo com desconfiança. Sendo assim, se preocuparam em delimitar seu espaço de ação, indicando a dinâmica de autoridade a ser estabelecida entre proprietário e vilicus.

Catão no capítulo 2 do seu De Agri Cultura, no qual orienta a respeito da visita do proprietário a sede, afirma que a primeira ação a ser tomada por ele, além dos rituais religiosos, seria a confrontação do vilicus sobre a situação produtiva em que se encontrava a villa. Logo, a visita funcionaria como a intervenção do proprietário na administração que o agente conduzia. Quando o proprietário visitava a propriedade ele deveria exigir do vilicus que lhe explicasse o estado das operações, a eficiência do trabalho, as condições de preservação da sede, o status da produção e as quantidades dos produtos (CATÃO, De Agri Cultura, 2.1-2). A visita funcionava como um lembrete de que o vilicus trabalhava subordinado a seu senhor, que the cobraria cada ação que tomara em sua ausência. Logo, além de limitar a área em que o agente poderia atuar, a autoridade do proprietário no De Agri Cultura de Catão seria exercida a partir das visitas como meio de prestação de contas.

Mais duas orientações de Catão são interessantes para analisar o exercício de autoridade do proprietário e as características de sua delegação. A primeira na qual 
Catão afirma que o vilicus não deveria pensar que sabe mais que o proprietário - essa recomendação se encontra logo em seguida da orientação de que o agente deveria cuidar e cumprir o que o proprietário ordenou (CATÃO, De Agri Cultura, 5.2). Em um modelo absenteísta de delegação ativa seria necessário que o proprietário demarcase sua autoridade como o mais capacitado para tomar as decisões necessárias ao funcionamento da propriedade. Mesmo na sua ausência o vilicus deveria seguir o curso de ação estabelecido a partir de sua avaliação em visita a villa. A segunda orientação diz respeito a só dar ouvido a quem o senhor ordenou - a orientação anterior a essa afirma que o vilicus só pode ser amigo dos amigos de seu senhor (CATÃO, De Agri Cultura, 5.2). Essa orientação demarca quem poderia dar opiniões sobre os meandros da administração da villa na ausência do proprietário, isto é, o agente só poderia acatar as sugestões dos indivíduos em quem seu senhor confiava. As decisões administrativas sobre a dinâmica da villa tinham, portanto, caráter privado, só delegaria o proprietário e aquele que ele permitisse delegar. O principal objetivo de Catão com essas orientações, a nosso ver, seria delinear aquilo que estava dentro e o que estava fora do escopo do vilicus, indicando o papel ativo, ainda que não constantemente presencial, do proprietário. Além disso, o autor delineia que o comportamento do agente deveria estar de acordo com a conduta administrativa do proprietário. A delegação não constituía, portanto, sinônimo de depositar nas mãos de um agente escravo o poder de tomar decisões por si mesmo, mas sim que essas decisões tivessem a marca do senhor, como se o escravo funcionasse como a extensão do proprietário. Logo, suas ações deveriam obrigatoriamente estar de acordo com as de seu superior.

A dinâmica de autoridade entre proprietário e vilicus no De Re Rústica de Varrão não é tão facilmente identificável. Isso porque o autor está mais preocupado em delinear as características necessárias ao agente e a relação que esse deveria estabelecer com os escravos. No entanto, uma orientação do autor pode nos indicar sua ideia a respeito do exercício de autoridade do proprietário e senhor. No capítulo 17 do primeiro livro do seu De Re Rustica o autor afirma que a boa vontade do vilicus deveria 
ser adquirida a partir de um tratamento que enxergasse o escravo além de sua condição de objeto, tratando-os com consideração (VARRÃO, De Re Rustica, 1.17.6), essa orientação possivelmente se relaciona ao contexto do século de escrita do tratado de Varrão. O século I a.C. foi envolvo por três grandes revoltas de escravos, sendo a Revolta de Espártaco de grandes proporções e próxima a cidade de Roma - essa revolta desmobilizou a organização de uma série de propriedades agrícolas com a adesão massiça de escravos rurais (BRADLEY, 1989, p.98-99). A escolha do autor de orientar que a autoridade tanto do vilicus quanto dos demais escravos em postos de comando na propriedade se estruturasse na legitimidade, na recompensa material e na ausência, o quanto fosse possível, da violência física, pode estar relacionado a esse panorama. Após as revoltas, sobretudo a de Espártaco, os senhores puderam vislumbrar do que os escravos seriam capazes caso fossem levados ao limite. Logo, deveriam ser cautelosos quanto à forma que exerciam sua autoridade. Possivelmente por essa razão Varrão não se ocupa em delinear os limites do agente e a recomendar que esses escravos (o vilicus e demais em cargo de supervisão) deveriam ser "conquistados" pelo proprietário, de modo que se tornassem seus aliados na administração da propriedade. O exercício da autoridade, portanto, nem sempre estava relacionado a imposições explícitas, mas também se traduzia em meios psicológicos, a partir da concessão de recursos recompensatórios, de modo a exercer influência sobre os indivíduos. Isso não significa, portanto, que Varrão realmente advogasse uma relação pessoal com os escravos, mas sim que se tratava de uma estratégia administrativa necessária para que o modelo vigente pudesse continuar em funcionamento.

Columella retoma a ideia catoniana de exercício de autoridade do proprietário a partir da delimitação da área de atuação do vilicus e da intervenção administrativa a partir da visita. Dos três autores Columella é aquele que mais demonstra desconfiança no chamado vilicus system, como já apontado. De acordo com o autor o modelo de exploração direta deveria ser empregado apenas para propriedades próximas o suficiente para que o proprietário pudesse visita-las em caráter diário, se possível - o 
arrendamento de terras deveria ser empregado nas propriedades distantes e sem possibilidade de intervenção cotidiana do proprietário (COLUMELLA, De Re Rustica, 1.7.6-7). Catão e Varrão não nos informa a respeito da assiduidade na qual o proprietário deveria visitar a villa, mas considerando de modo geral suas orientações não nos parecem defender visitas tão frequentes como Columella. O autor também retoma a ideia de Varrão de que seria preciso que o proprietário e senhor tratasse o vilicus (e os demais escravos) com consideração. No capítulo 8 do primeiro livro do seu $D e$ Re Rustica, Columella propõe uma combinação das estratégias de Catão e Varrão. De acordo com o autor, o proprietário deveria tratar com justiça e consideração o vilicus (e os demais escravos) e assegura que esse tipo de comportamento melhoraria a propriedade. Além disso, durante a visita deveria inspecionar cada parte da villa de modo a avaliar se sua ausência resultara no relaxamento da disciplina e da supervisão do trabalho, além de contabilizar os produtos, escravos e equipamentos. Essa prática deveria se tornar um hábito e asseguraria o sucesso do empreendimento e a submissão dos escravos, sobretudo do vilicus (COLUMELLA, De Re Rustica 1. 8.20).

A forma de demarcar a autoridade, delimitar as ações do vilicus e manter a ordem da propriedade no De Re Rustica de Columella seria a partir do equilíbrio entre a estratégia varroniana de tratamento com consideração e a estratégia catoniana de intervenção administrativa a partir das visitas, tendendo para a severidade da estratégia do Censor - o autor não cita, no entanto, os autores Catão e Varrão, é a análise comparada entre os documentos que nos permite tal conclusão. É interessante observar que Columella afirma que exercendo sua autoridade administrativa na propriedade de forma efetiva ao longo de sua vida o proprietário não estava desperdiçando seus anos, mas sim melhorando sua propriedade e, consequentemente, seu patrimônio. Além disso, a prática tornaria o senhor respeitado por seus escravos. Logo, Catão e Columella parecem concordar que a autoridade do proprietário se estruturava nas intervenções que realizava. 
A autoridade do proprietário em relação ao vilicus poderia, portanto, ser exercida de diferentes formas. Tanto tornando o agente um aliado do proprietário, fazendo-o sentir-se parte do sistema em que se encontrada, como é o caso de Varrão, quanto a partir de uma forma mais incisiva a partir da verificação e prestação de contas, quanto em Catão. Columella busca um equilíbrio entre as duas formas de agir, mas sua aparente desconfiança no vilicus system o leva a concentrar sua orientação na verificação e prestação de contas do agente. O que ambas as estratégias tem em comum é a demonstração de que ainda que ocupasse um cargo importante na dinâmica da propriedade, as ações do vilicus estavam subordinadas ao proprietário. Tal demonstração se mostra importante considerando o absenteísmo característico do sistema. Ainda que diariamente esses escravos dedicassem suas vidas para manter o funcionamento da propriedade, as decisões pertenciam a seus senhores. 0 estabelecimento de limites as ações de escravos em postos de comando constitui uma importante característica das relações escravistas. Seria preciso lembrar constantemente a esses sujeitos a sua inferioridade. Ainda que a figura do senhor não fosse física constantemente. A dinâmica da propriedade funcionaria, portanto, se o vilicus se submetesse a autoridade do senhor, assim como se os demais escravos se submetessem a autoridade do vilicus, conforme discutiremos na próxima seção.

\section{A dinâmica de autoridade entre Vilicus e demais escravos}

Carlsen afirma que a principal obrigação do vilicus na administração da propriedade seria gerir a mão de obra empregada na propriedade (CARLSEN, 1995, p. 70). Concordamos com a afirmativa, afinal, seriam os escravos e trabalhadores contratados aqueles responsáveis por todas as etapas da produção. Apesar do mesmo status jurídico que os demais, na dinâmica da villa o vilicus constituía a autoridade máxima e estava acima de qualquer outro escravo na cadeia hierárquica. Os agronômos orientam, portanto, sobre como o vilicus deveria estabelecer sua autoridade em relação aos demais escravos. 
NEARCD: Revista Eletrônica de Antiguidade 2020, Volume XII, Número I - ISSN 19882-8713

Núcleo de Estudas da Antiguidade -NEA

Universidade do Estada do Rio de Janeiro

ISSN 1982-8713

A estratégia central para compreender o estabelecimento dessa dinâmica de autoridade é a ideia de que o vilicus deveria agir de forma a legitimar a sua autoridade perante os demais escravos. Para tanto, os agrônomos deixam uma orientação clara, o vilicus deveria saber realizar todos os trabalhos que compunham as operações produtivas da propriedade. Mas do que saber, deveria realizá-las com frequência. Catão afirma que

Ele deve cuidar para que ele saiba como realizar todas as operações agrícolas, e realmente as realiza com freqüência, mas não a ponto de ficar exausto; assim fazendo, ele aprenderá o que se passa na mente de seus servos e eles realizarão seu trabalho com mais satisfação ${ }^{43}$ (CATÃO, De agri Cultura, 5,4-5).

Além da legitimação, essa prática poderia servir ainda como meio de estabelecer um diálogo entre o vilicus e os demais escravos. Catão não nos fornece muitos detalhes a respeito, mas podemos supor que tal diálogo seria uma forma do agente ter um conhecimento mais profundo acerca do cotidiano da propriedade e poder, assim, evitar conflitos, controlar aqueles que ultrapassassem os limites e estabelecer mecanismos para manter os escravos comprometidos com o trabalho. Varrão explica de forma mais clara a importância do conhecimento teórico e prático do vilicus para o exercício de sua autoridade, de acordo com o autor:

Além disso, é especialmente importante que os vilicus sejam homens com experiência em operações agrícolas; pois o vilicus não deve apenas dar ordens, mas também participar do trabalho, para que seus subordinados sigam seu exemplo e também entendam que há uma boa razão para ele estar acima deles - o fato de que ele é superior a eles em conhecimento ${ }^{44}$ (VARRÃO, De Re Rustica, 1.17.4).

\footnotetext{
${ }^{43}$ He must see to it that he knows how to perform all the operations of the farm, and actually does perform them often, but not to the poin t of becoming exhausted; by so doing he will learn what is in his servants' minds, and they will perform their work more contentedly.

44 Furthermore, it is especially important that the foremen be men who are experienced in farm operations; for the foreman must not only give orders but also take part in the work, so that his subordinates may follow his example, and also understand that there is good reason for his being over them - the fact that he is superior to them in knowledge.
} 
Isto é, Varrão considera que a autoridade exercida apenas de forma impositiva e sem base prática poderia ser mais facilmente questionada pelos demais. O vilicus só seria respeitado e suas orientações só seriam seguidas se os demais escravos acreditassem que o agente sabia a respeito daquilo que ordenava. Além disso, a execução das atividades por parte do vilicus serviria ainda de exemplo sobre como proceder. O vilicus deveria saber e demonstrar que sabia como forma de legitimar a sua posição. A ideia varroniana se assemelha com a definição de Herbet Simon a respeito da autoridade. De acordo com o autor, a autoridade levaria o subordinado querer seguir as orientações de seu superior, sem necessidade de nenhuma coerção ou recompensa (SIMON, 1997, p. 179). Consideramos que a orientação de Varrão aponte para esse sentido. Ademais, a experiência prática deveria ser somada à experiência de vida Varrão salienta que era mais provável que os escravos respeitassem a autoridade de alguém mais velho (VARRÃO, De Re Rustica, 1.17.4). Todas as características exigidas para ocupação do cargo possuíam, portanto, duas finalidades: uma obviamente relacionada à competência do escravo para o exercício de suas funções e outra relacionada à sua capacidade de ser respeitado pelos demais escravos, isto é, exercer sua autoridade de modo a controlar os sujeitos envolvidos na produção. No entanto, como discutiremos mais a frente, não seria só o conhecimento prático e teórico a legitimar a autoridade no De Re Rustica de Varrão, a recompensa também constituía um aspecto importante.

Columella no seu De Re Rustica nos informa a respeito da necessidade do conhecimento prático e teórico do vilicus ao afirmar que:

Mas seja quem esteja destinado a este negócio deve ser especializado neste e muito robusto para que possa ensinar os que estão sob suas ordens (e também a ele mesmo) a cumprir adequadamente as instruções dadas; pois, de fato, nada pode ser ensinado ou aprendido corretamente sem um exemplo e é melhor que o oficial de justiça seja 
NEARCD: Revista Eletrônica de Antiguidade 2020, Volume XII, Número I - ISSN 19882-8713

Núcleo de Estudas da Antiguidade -NEA

Universidade do Estada do Rio de Janeiro

ISSN 1982-8713

o mestre, não o aluno, ou seus trabalhadores ${ }^{45}$ (COLUMELLA, De Re Rustica, 11.1. 4).

O autor retoma a ideia de que o vilicus deveria servir como exemplo aos demais e dele deveria emanar o conhecimento e não ao contrário. Essa ideia, portanto, constitui uma estratégia estrutural na administração da villa no modelo vilicus system. A importância da gestão da mão de obra da propriedade por parte vilicus fica ainda mais evidente no De Re Rustica de Columella. O autor propõe uma gestão mais complexa para o emprego da mão de obra na villa. Para que a produtividade dos trabalhadores e a eficiência da produção fossem possíveis, seria preciso que o escravo designado para cada uma das funções contasse com as características físicas e intelectuais necessárias ao trabalho. Considerando que a escolha do escravo ideal para cada tipo de atividade constituía a base da alocação do trabalho escravo na propriedade no modelo administrativo columeliano, a responsabilidade daquele que efetuava tal alocação seria significativa, responsabilidade essa que estava a cargo do vilicus. Columella explica sua lógica no capítulo 11 do primeiro livro do seu De Re Rustica, no caso do apascentador do rebanho, por exemplo,

No caso do lavrador, inteligência, embora necessária, ainda não é suficiente a menos que a grandeza de voz e de porte o tornem formidável para o gado. No entanto, ele deve temperar sua força com gentileza, pois deve ser mais aterrorizante do que cruel para que o gado possa obedecer aos seus comandos e ao mesmo tempo durar mais, porque não se esgotam com as durezas do trabalho combinadas com o tormento do chicote ${ }^{46}$ (COLUMELLA, De Re Rustica, 1.11.2).

\footnotetext{
${ }^{45}$ But whoever is destined for this business must be very learned in it and very robust, that he may both teach those under his orders and himself adequately carry out the instructions wich he gives; for indeed nothing can be taught or learned correctly without an exemple, and it is better that the bailiff should be the master, not the pupil, or his labourers.

${ }^{46}$ In the case of the ploughman, intelligence, though necessary, is still not sufficient unless bigness of voice and in bearing makes him formidable to the cattle. Yet he should temper his strength with gentleness, since he should be more terrifying than cruel, so that the oxen may obey his commands and at the same time last longer because they are not worn out with the hardship of the work combined with the torment of the lash.
} 
NEARCD: Revista Eletrônica de Antiguidade 2020, Volume XII, Número I - ISSN 19882-8713

Núcleo de Estudas da Antiguidade -NEA

Universidade do Estado do Rio de Janeiro

ISSN 1982-8713

O autor afirma que o homem mais forte não pode obedecer a uma ordem a não ser que ele saiba o que fazer, assim como o mais habilidoso,

O mais importante neste tipo de superintendência é saber e avaliar quais deveres e tarefas devem ser impostos a cada pessoa; pois o homem mais forte não pode cumprir uma ordem a menos que saiba o que tem que fazer, nem o mais hábil se ele não tiver força. Portanto, a natureza de cada operação deve ser levada em consideração; pois algumas tarefas requerem apenas força, como mover e carregar cargas pesadas, outras requerem uma combinação de força e habilidade, como cavar, arar e cortar a grama e campos; para alguns, menos força e mais habilidade é aplicada como na poda e enxertia de um vinhedo, e para alguns alguns conhecimentos são de maior importância, por exemplo, na alimentação e tratamento de gado ${ }^{47}$ (COLUMELLA, De Re Rustica, 11.1.8).

A autoridade do vilicus no De Re Rustica de Columella também passa pelo conhecimento e pela legitimidade, de forma relativamente similar a Varrão. No entanto, a importância da alocação dos trabalhadores torna essas características ainda mais relevantes. O vilicus eficiente, preparado e que tomasse decisões pautadas em uma lógica produtiva teria mais chance de ser respeitado e de exercer sua autoridade de modo mais contundente. Possíveis inconsistências na conduta do agente poderiam significar insubordinação por parte dos escravos.

Os agrônomos nos informam ainda sobre outras estratégias a serem mobilizadas para o exercício da autoridade do agente em relação a mão de obra na propriedade. Catão no seu De Agri Cultura foca na relação de autoridade entre o vilicus e outra figura importante da dinâmica produtiva da villa, a vilica.

\footnotetext{
${ }^{47}$ The most important thing in this kind of superintendence is to know and estimate what duties and what tasks should be enjoined on each person; for the strongest man could not carry out an order, unless he knows what he has to do, nor the most skilful, if he lacks the strength. The nature therefore of each operation must be taken into consideration; for some tasks require strength only, such as the moving and carrying of heavy loads, others require a combination of strength and skill, as in digging and ploughing and mowing field crops and meadows; to some less strength and more skill is applied as in the pruning and grafting of a vineyard, and for some knowledge is of the chief importance, for instance, in the feeding and doctoring of cattle.
} 
NEARCD: Revista Eletrônica de Antiguidade 2020, Volume XII, Número I - ISSN 1982-8713

Núcleo de Estudas da Antiguidade -NEA

Universidade do Estada do Rio de Janeiro

ISSN 1982-8713

A vilica constituía a esposa ${ }^{48}$ do vilicus e era responsável, como nos informa o autor, por cuidar da estadia do proprietário e de sua esposa, manutenção da sede, dispensa e feitura de alimento em conserva (CATÃO, De Agri Cultura, 143). Devido as suas obrigações e a relação estabelecida com o vilicus, essa mulher ocupava um alto posto na hierarquia escrava. Catão salienta no capítulo relativo as suas obrigações sobre necessidade de submeter essa mulher a autoridade do vilicus, seu marido. (CATÃO, De Agri Cultura, 143).

O autor orienta a respeito das obrigações da vilica indicando em primeiro lugar, que o vilicus deveria cuidar para que sua esposa realizasse tais deveres (CATÃO, De Agri Cultura, 143). Acreditamos que Catão se dirija ao vilicus e não ao proprietário pois a frase seguinte afirma que "If the master has given her to you as wife, keep yourself only to her. Make her stand in awe of you. Restrain her from extravagance." (CATÃO, De Agri Cultura, 143). O exercício de autoridade do vilicus em relação a vilica no De Agri Cultura tem duas características, reproduz a dinâmica de autoridade do proprietário em relação ao vilicus, bem como do marido em relação a esposa. Logo, a vilica estaria duas vezes subordinada, a seu marido e seu chefe. Isso porque, assim como o proprietário precisaria controlar o vilicus em decorrência de sua posição importante, o mesmo

\footnotetext{
${ }^{48}$ A partir da análise de inscrições epigráficas Ulrike Roth defende a tese de que a vilica não constituía necessariamente a esposa do vilicus, mas sim outra agente da villa, subordinada ao vilicus, mas sem manter relações pessoais com ele. ROTH, U. The Female Slave in Roman Agriculture: Changing the Default. Nottinghan, Nottinghan University Press, 2003. Jesper Carlsen argumenta contra essa ideia e afirma que embora Roth esteja correta em afirmar que a vilica desempenhava um papel importante na dinâmica da villa, sua ideia de contester o relacionamento de marido e mulher entre vilicus e vilica não é convincente. CARLSEN, J. "The villica and Roman estate management". In: Land and Labour: Studies in Roman social and economic history. Roma: L'Emma do Bretschneider, 2013, p. 111-112. Concordamos com Roth que a vilica ocupava um lugar fundamental na dinâmica da propriedade, no entanto, considerando os documentos analisados, isto é, os tratados agrícolas de Catão, Varrão e Columella, as indicações de que o vilicus e a vilica constituíam um casal são claras. Essa orientação não consiste, a nosso ver, como uma forma de corrigir uma tendência da sociedade. Isto é, os agronômos latinos não prescrevem o relacionamento entre vilicus e vilica porque na prática esse relacionamento não acontecia, mas sim para reforçar uma prática já existente. Isso porque, caso a vilica constituísse uma agente pessoalmente independente do vilicus, ainda que profissionalmente subordinada a ele, seus poderes de ação possivelmente seriam maiores e a dinâmica de autoriedade se estruturaria de forma distinta na villa. Fosse esse o caso os agronômos apresentariam o cenário em seus tratados considerando a importância de ambos os agentes.
} 
NEARCD: Revista Eletrônica de Antiguidade 2020, Volume XII, Número I - ISSN 19882-8713

Núcleo de Estudas da Antiguidade -NEA

Universidade do Estada do Rio de Janeiro

ISSN 1982-8713

deveria ocorrer com a vilica. E, por outro lado, reforça a ideia de necessidade de submissão das mulheres em relação aos homens, sobretudo de esposas a seus maridos, independente de seu status.

Varrão salienta que a autoridade na villa, seja por parte do proprietário ou do vilicus, não deveria, a princípio, ser exercida de modo coercitivo, fosse para que os escravos realizassem seus deveres, ou quando cometessem algum tipo de delito, conforme apontado. Nas palavras do autor, "They are not to be allowed to control their men with whips rather than with words, if only you can achieve the same result." (VARRÃO, De Re Rustica, 1.17.5). O exercício da autoridade do vilicus no De Re Rustica de Varrão se concentra, portanto, na questão da legitimidade do agente a partir de seu conhecimento teórico e prático. No entanto, esse exercício também pode ser demonstrado a partir da capacidade do agente (proveninente de sua posição) de conceder recompensas aos escravos. Conforme o autor orienta no capítulo 17 do primeiro livro,

Eles são levados a possuirem mais interesse no trabalho ao serem tratados com mais liberdade em relação a alimentos, ou mais roupas, ou isenção do trabalho, ou permissão para pastorear seu próprio gado na fazenda, ou outras coisas desse tipo; de modo que, se alguma tarefa incomumente pesada fosse imposta, ou punição infligida a eles de algum modo, sua lealdade e sentimento de bondade para com o mestre podem ser restaurados pelo consolo derivado de tais medidas $^{49}$ (VARRÃO, De Re Rustica, 1.17.7).

Logo, o vilicus deveria ser respeitado e obedecido porque ele tinha a autoridade da concessão. Conforme apontado na seção anterior, o panorama de revoltas de escravos que ocorreu no século I a.C., sobretudo a Revolta de Espártaco, possivelmente influenciou a forma como Varrão concebe as dinâmicas de autoridade na villa. Sendo

\footnotetext{
${ }^{49}$ They are made to take more interest in their work by being treated more liberally in respect either of food, or of more clothing, or of exemption from work, or of permission to graze some cattle of their own on the farm, or other things of this kind; so that, if some unusually heavy task is imposed, or punishment inflicted on them in some way, their loyalty and kindly feeling to the master may be restored by the consolation derived from such measures
} 
assim, seria preciso reconsiderar alguns pontos da administração desse tipo de mão de obra no sistema da villa. A autoridade deveria, portanto, ser exercida a partir de formas alternativas. O vilicus deveria deixar de ser um carrasco e se tornar um homem que se mostrasse justo e capaz de liderar os demais, da mesma forma que, como apresentado na seção anterior, o senhor deveria lidar com o vilicus. Esse tipo de demonstração de autoridade teria, possivelmente, o objetivo de tornar o cotidiano menos conflituoso.

Assim como Varrão, Columella também associa a relação do vilicus com os demais escravos ao seu exercício de autoridade. Segundo o autor, o agente deveria evitar intimidade com os da casa e com estranhos (COLUMELLA, De Re Rustica, 11.1.23). Esta determinação já aparece em Catão (quando o autor afirma que a vilica não deve frequentar a casa dos vizinhos e que os amigos do proprietário devem ser os únicos com que o vilicus deveria se relacionar - CATÃO, De Agri Cultura, 143; 5.3). Essa recomendação é bastante interessante e tem, a nosso ver, dois objetivos. Em primeiro lugar, em relação aos estranhos, podemos supor que se trate de uma cautela necessária para que se evitassem traições contra o senhor, ou evitar que a atenção do vilicus fosse desviada para outros assuntos, ou ambas. Quanto aos de casa, a aproximação com escravos subordinados a ele poderia causar danos a sua figura de autoridade. Ao estabelecer laços de amizades com os escravos essa esfera pessoal atrapalharia as operações da propriedade, fosse pelos possíveis amigos do vilicus não respeitarem suas ordens, fosse porque o próprio vilicus poderia privilegiar de forma indevida algum escravo. Columella demarca uma das características mais importantes e perversas da escravidão, a negação, pelo menos em teoria, da sociabilidade do escravizado. $O$ vilicus e os demais escravos teriam apenas que cumprir as suas obrigações, era para isso que existiam.

O exercício de autoridade do vilicus em relação aos demais escravos, e também em relação aos trabalhadores contratados, era extremamente importante para a manutenção da ordem na propriedade. Por essa razão os autores orientam a respeito de mecanismos que tornassem tal exercício eficiente e, ao mesmo tempo, compatível 
com o modelo administrativo proposto. Grande parte da administração da villa estava voltada para a administração de relações pessoais dos sujeitos envolvidos no processo produtivo.

\section{Considerações finais}

A delegação ativa constituía, a nosso ver, uma estratégia estrutural para a administração da villa. Para que tal dinâmica funcionasse seria preciso um agente que pudesse ser controlado pelo proprietário e que pudesse controlar os demais escravos e trabalhadores contratados. O vilicus constitui, portanto, a figura de autoridade do quadro de escravos empregados na propriedade que tornava possível que a elite romana explorasse a terra de forma direta, sem precisar arrenda-la, mas, ao mesmo tempo, sem que precisasse estar cotidianamente presente nas propriedades. Logo, não seria absurdo considerar que o vilicus constituía um agente fundamental para que o sistema econômico da villa pudesse funcionar. Sua importância é atestada nas orientações dos agrônomos nos tratados analisados.

O papel do vilicus só funcionaria, no entanto, se o escravo escolhido para o cargo atendesse a duas prerrogativas, agisse dentro do escopo que lhe fora estabelecido e de acordo com a forma de proceder de seu senhor, isto é, reconhecendo sua autoridade. E, ao mesmo tempo, se fosse capaz de subordinar os demais escravos e faze-los trabalhar de forma satisfatória, exercendo sobre eles a sua autoridade. Esse agente que sustentaria o modelo proposto pelos agronômos seria ao mesmo tempo subordinado e aquele que subordinaria e constituía uma das muitas contradições que compunham o mundo escravo na sociedade romana. 
ISSN 1982-8713

\section{Referências Bibliográficas}

\section{Documentação}

CATO, On Agriculture \& VARRO, On Agriculture. Tradução: Harrison Boyd Ash e Willian Davies Hooper. Loeb Classical Library L 283. Cambridge, MA: Harvard University Press, 1935.

COLUMELLA, On Agriculture. Trad. Harrison Boyd Ash. Loeb Classical Library 361; 407; 408. Cambridge, MA: Harvard University Press, 1941.

PLUTARCH. Lives, Volume II: Themistocles and Camillus. Aristides and Cato Major. Cimon and Lucullus. Trad. Bernadotte Perrin. Loeb Classical Library 47. Cambridge, MA: Harvard University Press, 1914.

\section{Bibliografia}

ANDREAU, J. Sur le choix économiques des notables romains. In: ANDREAU J.; FRANCE, J; PITTIA, S. (eds.) Mentalités et choix économiques des romains. (Scripta Antiqua 7.). Bordeaux: Ausonius, 2004.

AUBERT, J. J. Managers of agricultural estates. In: Business managers in ancient Rome: $a$ social and economic study of Institores, 200 B.C.- A.D. 250. Cambridge: Cambridge University Press, 1994.

BRADLEY, K. Slavery and rebelion in the Roman world, 140 b.C.-70b.C. Indiana: Indiana University Press, 1989.

BRADLEY, K. Slavery and society at Rome. Cambridge: Cambridge University Press, 1994.

CARLSEN, J. Vilici and Roman Estate Managers until AD 284. Roma: L'Erma di Bretschneider, 1995.

CARLSEN, J. Land and Labour. Studies in Roman social and economic history. Roma: L'Emma do Bretschneider, 2013.

JOSHEL, S. "Slavery and Roman literary culture". In: BRADLEY, K; CARTLEDGE, P. (org.) The Cambridge World History of Slavery. V.1. Cambridge: Cambridge University Press, 2011.

ROTH, U. The Female Slave in Roman Agriculture: Changing the Default. Nottinghan, Nottinghan University Press, 2003. 
NEARCD: Revista Eletrônica de Antiguidade 2020, Volume XII, Número I - ISSN 19882-8713

Núcleo de Estudas da Antiguidade -NEA

Universidade do Estada do Rio de Janeiro

ISSN 1982-8713

SIMON, H. Administrative behavior: a study of decision, making processes in administrative organizations. 4a edição. New York: The Free Press, 1997.

TREVIZAM, M. Introdução, tradução e notas. In: VARRÃO. Das coisas do campo. Tradução de Matheus Trevizam. Campinas: Editora Unicamp, 2012. 